\title{
Search for antigen in rheumatoid synovial macrophages
}

\author{
L. A. RUNGE \\ From the Rheumatic Disease Unit, Ottawa General Hospital, Ontario, Canada
}

\begin{abstract}
Runge, L. A. (1976). Annals of the Rheumatic Diseases, 35, 133-137. Search for antigen in rheumatoid synovial macrophages. Peripheral blood monocytes and synovial macrophages obtained from 21 patients with rheumatoid arthritis and from 13 controls were cultured with autologous peripheral blood lymphocytes and stimulation measured by thymidine uptake. Rheumatoid macrophages and monocytes induced a small but significant degree of lymphocyte transformation, and those from the controls did not. The degree of stimulation appears to be more consistent with the nonspecific effect of lymphocyte activating factor, rather than with the presence of a specific synovial antigen.
\end{abstract}

Macrophages play an important immunological role (Unanue, 1972) by presenting antigens to lymphocytes (Cline and Swett, 1968). Indeed, the macrophagelymphocyte aggregate seen in tissue culture has been shown to be a site for passage of antigen to lymphocyte (Bona and others, 1972) and for lymphocyte transformation (Sulitzeanu and others, 1971). Macrophage-lymphocyte aggregates appear early in the life of rheumatoid synovial tissue culture and may indicate the presence of antigen in the synovial macrophage. This study assesses the degree of antigenic processing of rheumatoid synovial macrophages by measuring their ability to induce autologous lymphocyte transformation.

\section{Material and methods}

PATIENTS

Subjects were selected from patients admitted for joint surgery and from those attending the Rheumatic Disease Unit Out Patient Department with synovial effusions. The 21 patients with rheumatoid arthritis all had definite or classical disease (Ropes and others, 1959) except for one with 7 years of polyarticular juvenile rheumatoid arthritis. Nine rheumatoid synovial tissues and 21 synovial fluids were studied. The 13 controls consisted of 5 patients with osteoarthrosis, 3 with septic arthritis, 2 with posttraumatic disease, and one each with ankylosing spondylitis, palindromic rheumatism, and villonodular synovitis. Synovial tissues were studied in 7 cases and synovial fluid in 6. After obtaining informed consent, the joint fluid was aspirated and $30 \mathrm{ml}$ of blood obtained.

Initially medium containing penicillin and streptomycin was used for the following procedures; however, when improved facilities became available, antibiotics were discontinued and all contaminated cultures discarded.

\section{LYMPHOCYTE PREPARATION}

$30 \mathrm{ml}$ of whole blood were prepared for further processing by defibrination with glass beads or anticoagulation with preservative-free heparin (Fisher Scientific, Fair Lawn, N. J.). After removing the serum or plasma, the volume of cells was doubled with Eagle's Minimal Essential Media (Grand Island Biological, Grand Island, N.Y.) containing glutamine ( $2 \mathrm{mmol} / \mathrm{ml})$, sodium bicarbonate $(25 \mu \mathrm{mol} / \mathrm{ml})$, and HEPES buffer (25 $\mu \mathrm{mol} / \mathrm{ml}$ ) (Calbiochem, San Diego, U.S.A.). The cell mixture was layered on a Ficoll (Pharmacia Fine Chemicals, Uppsala, Sweden) -Hypaque gradient and lymphocytes separated by centrifugation at $400 \mathrm{~g}$ for 10 minutes (modified from Toh and others, 1973). This technique usually yielded $20-30 \times 10^{6}$ white cells containing 70-90\% lymphocytes. By culturing these cells for at least 3 hours in plastic flasks (Falcon Plastics, Oxnard, California) in medium containing bicarbonate, HEPES, and $30 \%$ autologous serum (growth medium), the monocytes (adherent cells) were separated from the lymphocytes. Nonadherent lymphocytes were concentrated to $10^{7} / \mathrm{ml}$ and frozen in liquid nitrogen in growth medium containing $10 \%$ dimethyl sulphoxide (Canlab, J. T. Baker). The frozen lymphocytes were rapidly thawed and washed when required, yielding $80-95 \%$ viable cells by trypan blue dye exclusion.

\section{MONOCYTE PREPARATION}

Monocytes were prepared from whole blood as mentioned above. After lymphocyte removal, the cultures were sustained in growth medium containing 30\% healthy AB serum (kindly supplied by Canadian Red Cross Laboratories, Ottawa). Most cultures became granular after 
10 days and were not used thereafter. The phagocytosis of heat-treated candida tested monocyte function, yielding uptake by $20-30 \%$ of the monocytes compared with $<10 \%$ uptake with cells derived from predominantly fibroblast cultures.

SYNOVIAL MACROPHAGE PREPARATION

(SYNOVIAL TISSUE)

Fat trimmed synovial specimens were minced with scalpels in a sterile environment. The minced synovium was cultured and macrophages isolated by removing the explants after 7-10 days. The minced synovium was later digested by collagenase $0.5 \mathrm{~g}$ (type II, Worthington Biochemical, Freehold, N.J.) and hyaluronidase 5000 units (Sigma Chemical, St. Louis, Mo.) in $100 \mathrm{ml}$ of Eagle's basic salt solution (EBSS) using a magnetic stirrer in a sterile flask (modified from Yamada and Ambrose, 1966). The latter procedure yielded more cells and was used exclusively once developed. Initially, growth medium contained $30 \%$ autologous serum; however, once the macrophages became attached to the culture flask, healthy AB serum was used. Trypsinization with EDTA or EBSS containing $\mathbf{0 . 3 \%}$ lignocaine (Xylocaine) removed the macrophages which were tested for phagocytosis as were the monocytes described above, achieving essentially the same results. These cultures were therefore macrophage enriched; contaminating fibroblast and perhaps some lymphocytes proved impossible to remove.

SYNOVIAL MACROPHAGE PREPARATION

(SYNOVIAL FLUID)

Synovial effusions yielded macrophages after centrifugation of the fluid, washing with growth medium, and adherence of the cells to plastic culture flasks. Visible red cells or polymorphonuclear cells present in excess of $90 \%$ were partially removed by separation on a Ficoll-Hypaque density gradient as done for lymphocytes described above. Growth medium initially contained 30\% autologous serum, AB serum being used for the duration of the culture. Contaminating polymorphonuclear leucocytes usually died within 3 days of culture.

MACROPHAGE-LYMPHOCYTE MIXED CULTURE Synovial macrophage cultures free of nonadherent cells were trypsinized, washed, and concentrated to $10^{5} / \mathrm{ml}$ in growth medium containing $30 \%$ AB serum. $0.1 \mathrm{ml}$ aliquots $\left(10^{4}\right.$ macrophages) were placed in plastic Beckman microfuge tubes (Beckman Instruments, Toronto) followed by $0.1 \mathrm{ml}$ aliquots of lymphocytes $\left(10^{5}\right.$ cells). These concentrations produced maximum lymphocyte stimulation using heterologous macrophages. Control cultures consisted of lymphocytes alone, lymphocytes and autologous monocytes, lymphocytes and heterologous macrophages, and lymphocytes with monilia (dialysed
Dermatophytin O, Hollister-Stier Laboratories, Spokane, WA.) and PHA (Difco Phytohemagglutinin M, Detroit, Mich.).

After 6 days, 0.8 $\mu \mathrm{Ci}$ thymidine (Picker X-ray Engineering, St. Laurent, Quebec) was added, the cultures were harvested 18 hours later (precipitated with trichloracetic acid and solubilized) and counted in a liquid scintillation counter (Searle Isocap/300, 6868 liquid scintillation system). Usually each group contained three or more cultures. Occasionally when quantity permitted, excess macrophages were cultured again and the experiment repeated a few days later.

\section{STATISTICS}

At least three cultures were made for any one group within an experiment, and the mean value used for further analysis. By means of the paired Student's ' $t$ ' test, the difference between stimulated and unstimulated cultures for both rheumatoid patients and controls was assessed. The difference in degree of stimulation between rheumatoid and control cultures was assessed by comparing stimulation ratios with the unpaired Student's ' $t$ ' test, as were the difference in age and duration of arthritis. These values were calculated using a Wang 500 programmable calculator (Wang Laboratories, Tewksbury, Mass.). The significance of differences between rheumatoid patients and controls with respect to presence of rheumatoid factor and sex were calculated by the $\chi^{2}$ test.

\section{Results}

Table I shows the differences between the rheumatoid patients and controls with respect to number studied, mean age, duration of arthritis, sex, and presence of rheumatoid factor. The absence of rheumatoid factor in the control group was not unexpected. Unfortunately, the rheumatoid group contained significantly more women, and were both older and had had arthritis longer than the control group.

Table II shows the unstimulated values (cpm) and stimulation ratios-mean $\mathrm{cpm}$ with antigen divided by mean cpm unstimulated. The number of observations are shown, and the 3rd and 6th rows show the degree of significance by which the stimulated cultures exceed that of the unstimulated cultures. PHA, monilia antigen, and heterologous macrophages significantly increased the cpm for both rheumatoid and control lymphocytes, but the degree of stimulation did not differ between the two groups.

Peripheral blood monocytes and synovial macrophages induced a small but significant degree of

Table I Clinical differences between patients with rheumatoid arthritis $(R A)$ and controls

\begin{tabular}{|c|c|c|c|c|c|}
\hline & No. & $\%$ Female & $\begin{array}{l}\text { Mean age } \pm \\
S D(\text { years })\end{array}$ & $\begin{array}{l}\text { Mean duration } \pm \text { arthritis } \\
\text { (years) }\end{array}$ & $\begin{array}{l}\% \text { Positive } \\
\text { rheumatoid factor }\end{array}$ \\
\hline $\begin{array}{l}\text { RA } \\
\text { Controls } \\
\text { Difference } \\
\quad \text { RA vs. controls (P) }\end{array}$ & $\begin{array}{l}21 \\
13\end{array}$ & $\begin{array}{l}76 \\
15 \\
<0.01\end{array}$ & $\begin{array}{l}53 \pm 16 \\
41 \pm 14 \\
<0.025\end{array}$ & $\begin{array}{r}10 \pm 9 \\
3 \pm 5 \\
<0.005\end{array}$ & $\begin{array}{r}38 \\
0 \\
<0.02\end{array}$ \\
\hline
\end{tabular}


Table II Unstimulated values (cpm) and stimulation ratios of patients with rheumatoid arthritis (RA) and controls

\begin{tabular}{|c|c|c|c|c|c|c|c|}
\hline & \multicolumn{7}{|c|}{ Stimulation ratios } \\
\hline & $\begin{array}{l}\text { Unstimulated } \\
(\text { cpm) }\end{array}$ & $\frac{\text { Mono }}{\text { Control }}$ & $\frac{\text { Macro }}{\text { Control }}$ & $\frac{\text { Macro }}{\text { Mono }}$ & $\frac{P H A}{\text { Control }}$ & $\frac{\text { Monilia }}{\text { Control }}$ & $\begin{array}{l}\text { Heterologous } \\
\text { Macro } \\
\text { Control }\end{array}$ \\
\hline \multirow{2}{*}{$\begin{array}{l}\text { RA, no. } \\
\text { observations } \\
\text { Mean } \pm \text { SD } \\
\text { Significance } P \\
\text { (paired ' } t \text { ' test) }\end{array}$} & \multirow[t]{2}{*}{$\begin{array}{l}30 \\
984 \pm 704\end{array}$} & $\begin{array}{l}27 \\
1.94 \pm 1.86\end{array}$ & $\begin{array}{l}32 \\
2 \cdot 56 \pm 3 \cdot 23\end{array}$ & $\begin{array}{l}29 \\
1.54 \pm 1.05\end{array}$ & $\begin{array}{l}30 \\
48 \cdot 14 \pm 38 \cdot 76\end{array}$ & $\begin{array}{l}27 \\
9 \cdot 07 \pm 13 \cdot 55\end{array}$ & $\begin{array}{l}15 \\
11 \cdot 54 \pm 7 \cdot 91\end{array}$ \\
\hline & & $<0.05$ & $<0.01$ & NS & $<0.01$ & $<0.01$ & $<0.05$ \\
\hline \multirow{2}{*}{$\begin{array}{l}\text { Control, no. } \\
\text { observations } \\
\text { Mean } \pm \text { SD } \\
\text { Significance P } \\
\text { (paired 't' test) }\end{array}$} & \multirow[t]{2}{*}{$\frac{14}{2439} \pm 2883$} & $\begin{array}{l}13 \\
1 \cdot 40 \pm 0.85\end{array}$ & $\begin{array}{l}14 \\
1.63 \pm 1.56\end{array}$ & $\begin{array}{l}13 \\
1 \cdot 17 \pm 0.93\end{array}$ & $\begin{array}{l}14 \\
44 \cdot 6 \pm 62 \cdot 35\end{array}$ & 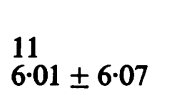 & $\begin{array}{l}5 \\
20 \cdot 39 \pm 19 \cdot 24\end{array}$ \\
\hline & & NS & NS & NS & $<0.01$ & $<0.02$ & $<0.05$ \\
\hline \multirow{3}{*}{$\begin{array}{l}\text { Ratio } \frac{\text { RA }}{\text { Control }} \\
\text { No. of } \\
\text { observations } \\
\text { Significance P } \\
\text { unpaired ' } t \text { ' test }\end{array}$} & 0.41 & $1 \cdot 39$ & $1 \cdot 57$ & $1 \cdot 32$ & 1.08 & $1 \cdot 51$ & 0.56 \\
\hline & 34 & 40 & 46 & 42 & 44 & 38 & 20 \\
\hline & $<0.02$ & NS & NS & NS & NS & NS & NS \\
\hline
\end{tabular}

stimulation in the rheumatoid group only. The absolute value of the mean rheumatoid macrophage stimulation was somewhat higher than the monocyte value, 2.56 vs. 1.94 , but this difference was not significant as noted by the macrophage stimulation to monocyte stimulation ratio.

Nine experiments with rheumatoid macrophages produced a macrophage/monocyte ratio greater than 2. When compared with the 14 experiments in which the stimulation ratio measured less than 1 , no significant differences were found with respect to age of the patient or duration of the arthritis. The stimulating macrophages tended to be from patients who were rheumatoid factor-positive ( $55 \%$ vs. $25 \%$ ), and derived from synovial tissue rather than synovial fluid ( $50 \%$ vs. $30 \%)$.

\section{Discussion}

The possibility that macrophages play an active role in maintaining synovitis has been studied previously. Macrophage cytoplasmic membranes localize antigens in experimental immune synovitis. In ovalbumin-sensitive rabbits the antigen may be found on the synovial fluid macrophage surface for periods up to one month after intra-articular injection of ovalbumin (Webb and others, 1972). Such a mechanism as shown by autoradiography may be at work in rheumatoid synovitis; however, as the antigen and antibody if present are unknown, attempts to demonstrate it by antibody dependent methods may be misleading. The relevant antibody may be present in small amounts only in the serum or not at all, especially if the disease occurs in antigen excess.
Autologous lymphocyte stimulation was chosen to detect the antigen, thereby sidestepping problems with low titre antibody. Lymphocyte stimulation occurs to a wide variety of antigens and can reasonably be expected to occur if the antigen is present.

Synovial macrophages proved difficult to obtain without the possibility of reducing their antigenic load either by trypsinization or prolonged culture. Nevertheless, these same macrophages induced marked stimulation of heterologous lymphocytes. The procedures used must have caused retention of some macrophage cell surface characteristics. In some experiments lignocaine (2) and mechanical scraping (2) were used to remove macrophages without a noticeable change in the results. The possibility nevertheless remains that the important antigen had been destroyed.

Rheumatoid monocytes and macrophages, especially those from synovial tissue induced a definite but barely significant degree of lymphocyte stimulation when compared with nonstimulated autologous lymphocyte cultures. The amount of stimulation did not differ significantly from lesser degrees found in nonrheumatoid disease, thus tending to negate this finding as a phenomenon specific to rheumatoid arthritis. The degree of stimulation in rheumatoid arthritis did not approach that of a more conventional stimulus, namely monilia antigen. Either the 'rheumatoid antigen' is in very low concentration or there is a better explanation for the lymphocyte stimulation.

The stimulation induced by rheumatoid macrophages appears not to be a phenomenon restricted to synovial cells, as rheumatoid peripheral blood monocytes also induced a significant degree of 
stimulation. The ability of synovial macrophages to stimulate lymphocytes would not therefore appear to be due to the presence of a unique synovial antigen.

Mitogen-stimulated macrophages nonspecifically increase lymphocyte transformation via a soluble mediator previously described as lymphocyte activating factor (LAF) (Gery and Waksman, 1972). Macrophage enrichment of lymphocyte culture increases baseline thymidine uptake, and that from BCG treated animals are more active than that from controls (Mitchell and others, 1973). The small degree of stimulation noted here is consistent with the effect of macrophage-produced LAF. It may be that immune complex phagocytosis by rheumatoid macrophages (Kinsella, Baum, and Ziff, 1970) induces LAF release. The tendency for macrophages from rheumatoid factor-positive patients to induce more stimulation may be due to the association of rheumatoid factor with larger immune complexes, more complement fixation (Winchester, Agnello, and Kunkel, 1971), and consequently increased phagocytosis. The mild lymphocyte stimulation may therefore reflect nonspecific immune complex macrophage activation rather than the presence of a specific synovial antigen.

The rheumatoid synovial fluid macrophagelymphocyte aggregates have been studied by quantitating the rosette formation. Synovial fluid macrophages form rosettes with synovial lymphocytes more so than do rheumatoid or nonrheumatoid blood monocytes or synovial macrophages from non- rheumatoid effusions (Hepburn, McDuffie, and Ritts, 1974). The fact that rosetting was not associated with increased lymphocyte thymidine uptake is consistent with the results reported here showing no increased lymphocyte stimulation due to rheumatoid monocytes or macrophages compared with nonrheumatoid controls. Perhaps the use of synovial macrophages as opposed to synovial fluid macrophages would have increased the difference between rheumatoid patients and controls.

The lymphocyte rosette forming rheumatoid synovial macrophage by scanning electron microscopy will not only attract autologous lymphocytes, but heterologous nonrheumatoid ones as well (Webb and others, 1975). These heterologous lymphocytes may be attracted nonspecifically to macrophages due to histocompatibility antigens. In any case, the rosetting of synovial fluid macrophages does not necessarily indicate the presence of an antigen specific for rheumatoid arthritis.

The existence of a 'rheumatoid specific antigen' therefore remains uncertain by the method of macrophage rosetting or lymphocyte stimulation. This study tried to identify a cell type with antigen like activity in order to proceed with more specific virological investigations. The evidence suggests that the synovial macrophage is not such a cell type.

The valuable technical assistance of Mrs. M. Ratcliffe is gratefully acknowledged. This study was supported by the Medical Research Council of Canada, Grant no. MA-5017.

\section{References}

Bona, C., Anteunis, A., Robineaux, R., and Astesano, A. (1972) Immunology, 23, 799 (Transfer of antigenic macromolecules from macrophages to lymphocytes)

Cline, M. J., AND SwETt, V. C. (1968) J. exp. Med., 128, 1309 (The interaction of human monocytes and lymphocytes)

Gery, I., AND WAKSMAN, B. H. (1972) Ibid., 136, 143 (Potentiation of T lymphocyte response to mitogens. 2. The cellular source of potentiating mediators)

HePBURN, B., MCDuffie, F. C., AND RITTs, R. E., JR. (1974) Arthr. and Rheum., 17, 1026 (The macrophagelymphocyte rosette: its increased incidence among cells from rheumatoid synovial fluid)

Kinsella, T. D., BAUM, J., AND ZifF, M. A. (1970) Ibid., 13, 734 (Studies of isolated synovial lining cells of rheumatoid and non rheumatoid synovial membranes)

Mitchell, M. S., KirkPatrick, D., MARGolit, B. M., AND Gery, I. (1973) Nature New Biol., 243, 216 (On mode of action of BCG)

Ropes, M. W., Bennett, G. A., Cobb, S., Jacox, R., and Jessar, R. A. (1959) Ann. rheum. Dis., 18, 49 (Diagnostic criteria for rheumatoid arthritis. 1958 revision)

Sulitzeanu, D., Kleinman, R., Benezra, D., Gery, I. (1971) Nature New Biol., 229, 254 (Cellular interactions and the secondary response in vitro)

Toh, B. H., Roberts-Thomson, I. C., Mathews, J. D., Whittingham, S., and Mackay, I. R. (1973) Clin. exp. Immunol., 14, 193 (Depression of cell mediated immunity in old age, and the immunopathologic diseases, lupus erythematosus, chronic hepatitis, and rheumatoid arthritis)

UNANUE, E. R. (1972) Advanc. Immunol., 15, 95 (The regulatory role of macrophages in antigenic stimulation)

Webb, F. W. S., Goldberg, L. S., Bluestone, R., and Pearson, C. M. (1972) Brit. J. exp. Path., 53, 608 (Retention of antigen by rabbit synovial macrophages)

-, Baker, M., Weisbart, R., Bluestone, R., ANd Goldberg, L. (1975) Ann. rheum. Dis., 34, 38 (Macrophagelymphocyte clustering in rheumatoid arthritis) 
Winchester, R. J., Agnello, V., Kunkel, H. G. (1971) J. Exp. Med., Suppl. 286 S (Occurrence of gamma globulin complexes in serum and joint fluid of rheumatoid arthritis patients: use of monoclonal rheumatoid factors as reagents for their demonstration)

Yamada, T., AND Ambrose, E. J. (1966) Exp. Cell. Res., 44, 634 (Preparations of cell suspensions from tissues using collagenase and hyduronidase, especially for measuring the electrical charges of surface membranes of mammalian cells) 